\title{
Visualization for Decision Support on North Texas Projects
}

\author{
Cameron Schmeits $^{1 *}$ and Nabeel Khwaja, P.E. ${ }^{2}$ \\ ${ }^{1}$ Research Associate, Center for Transportation Research, \\ The University of Texas at Austin \\ ${ }^{2}$ Research Engineer, Center for Transportation Research, \\ The University of Texas at Austin \\ ${ }^{1}$ cameron.schmeits@mail.utexas.edu, ${ }^{2}$ khwaja@mail.utexas.edu
}

\begin{abstract}
Public-Private Partnerships provide tools to public sector entities for partnering with the private sector and realizing the benefits of private capital, equitable risk allocation, revenue risk sharing, and the ability to rapidly deliver large and complex projects with innovations in design and construction. Innovative design proposals on complex projects in a fast paced delivery environment create additional challenges for the owner. Use of state-of-the-art visualization tools can significantly aide in reviewing innovative design approaches in a timely manner. Visualization has been used on the Texas Department of Transportation's LBJ Express and North Tarrant Express projects in the Dallas FortWorth metroplex in several ways. However, its valuable role in supporting decisions regarding innovative design has not been documented before. Concise and easily understood visualizations that integrated all the relevant information were very valuable. Rendered drive-through animations were able to eliminate concerns regarding visibility of signage so the owner's team could focus on other challenges of the project. The rendered drive-through animations also provided clear information about visibility of an ornamental rail for meaningful discussion between the public and private entity owner.
\end{abstract}

Keywords: Visualization, Transportation, Highway, Construction, Public Private Partnership

\section{Introduction}

Visualization has numerous applications in the transportation sector. This paper specifically focuses on the value of visualization in assisting a public entity owner review complex design information during the delivery phase of very large public-private partnership (PPPs). The Texas Department of Transportation (TxDOT) received legislative authority for PPPs from the 78th Texas legislature in 2003. This authority was subsequently refined by successive legislatures. PPPs provide an additional tool for TxDOT to deliver infrastructure improvement projects. According to TxDOT, PPPs accelerate the delivery of a project because several tasks, such as design and construction, are completed simultaneously [1]. Simultaneous completion of multiple tasks is possible because the public-sector owner contracts with one single entity to design and construct the infrastructure project. On some projects operations and/or maintenance is part of the PPP as well. Typically, in a traditional delivery one entity develops the design, another performs construction and then the public owner maintains the infrastructure. The accelerated financing leads to much larger projects that affect an entire region [1]. This is because additional funding from private sources enables projects to be built as one rather than several as financing is allocated. [2]. The private sector entity employs several tools and

Received (July 28, 2017), Review Result (September 21, 2017), Accepted (October 12, 2017)

${ }^{*}$ Corresponding Author 
techniques to achieve schedule savings. These include the overlap in the design and construction phases as mentioned above, but also innovative design solutions [2]. The public-sector entity responsible for the infrastructure project has to balance somewhat competing needs. In addition to quality concerns, the public sector entity has to ensure that the innovative design proposals do not reduce project scope as stipulated in the contract; will not adversely impact the traveling public during the construction phase; will meet the future needs of the infrastructure and planned interfaces with adjacent infrastructure projects without adversely affecting safety and quality. Increasingly complex architectural requirements are being added to the contracts to meet the desires of the regional stakeholders as well. Lastly, but still of importance, the footprint of the owner's team dedicated to these projects during the delivery phase is limited. For example, there were only five engineers as dedicated office staff assigned to the $\$ 2.6$ billion LBJ Express project during the five years of its delivery. Additional engineering was occasionally augmented with shared staff from specialized functions; however, the actual owner team assigned to the project never exceeded five engineers.

Visualization has been used on the LBJ Express and North Tarrant Express projects in the Dallas Fort- Worth metroplex in several ways. However, its valuable role in supporting decisions regarding innovative design has not been documented before. Two of these areas include signage visibility and acceleration and merging distances. Several aspects of visualization have quickly become mainstream in the last few years. However, as the case studies in this paper document, its use on fast-paced projects is now helping the owners review innovative design and make decisions in a timely manner.

\section{Literature Review}

Visualization as a communication tool for design information is well documented in O'Brien et al., Khwaja and Schmeits, Liapi, and Kim et al., [3-6]. O'Brien et al., and Khwaja and Schmeits also document the benefits of analyzing construction sequencing through 4D construction animations [3] [4]. This paper focuses on analyzing the proposed design with 3D visualization. While this paper looks at how the proposed design will be visible to the driver after construction, it needs to be clarified that this visual modeling was conducted without the aide of expensive driving simulators. Driving simulators are used to analyze drivers' behavior, but can also be used for analyzing designs. For reference, Upchurch et al. analyzed the driver performance (missed exits, departure from center line, lane change locations, etc.,) on the Central Artery - Tunnel project in Boston [7]. That project also used the driving simulator to discern issues such as signs that were not apparent on plan sheets. [7].

Several papers researched how driving simulators, virtual reality, or visualization can be helpful during the design phase for supporting geometric design, signing review, or for safety review/audits. This includes Consolazio where he created a 4D drive-through of a portion of I-280 eastbound through Newark, NJ where reviewers at the New Jersey Department of Transportation (NJDOT) traffic division evaluated proposed signing from a driver's perspective. [8]. Consolazio demonstrated how using visualization from a driver's perspective for reviewing signage before construction could avoid costly changes [8]. Han et al used virtual reality to study passing sight distance and concluded highway designs and operational modeling benefited from simulation on virtual reality based visualization platforms [9]. Upchurch et al., analyzed freeway guide signs for the Central Artery-Tunnel project in Boston during the design phase of the project by using a driving simulator and recommended sign designers use a driving simulator as a tool when planning highway guide signs [7]. Hassan et al., used generalized 3D projections to do analytical reviews of how horizontal and vertical curves interact [10]. Santiago-Chaparro et al., tried to develop a framework for using driving simulators for virtual road safety audits. They concluded creating a framework for board safety audits is challenging [11]. 
Driving simulators and visualizations looking at geometric design review during the design process seems to be well researched. However, this paper details the implementation of driver-perspective visualization during the delivery phase of major PPP projects where time is constrained and stakeholder buy-in is desired.

\section{Methodology}

\subsection{Project Organization}

The research documented in this paper was in support of a public entity owner on a PPP during the delivery phase. During the delivery phase of the project both detailed design and construction sequencing \& phasing is developed as seen in Figure 1. The private-entity as part of the PPP develops the detailed design. The private-entity can modify the design to achieve better construction performance and/or reduce costs with the public owner sharing in the savings with approval from the public entity owner and possible additional environmental review. Also, as the design and/or sequencing information propagate out into the greater public that travels the corridor, ideas about improvement became part of the discussion. Some of the ideas for improvements for the project have significant potential for being useful and lead to changes during the delivery phase. It is in this very dynamic phase where timely visualization can be very useful for the public entity owner. The delivery phase on the projects referenced in this paper is approximately five years or less. When compared to the traditional delivery model this duration provides an extremely expedited delivery and reduces time available for owner reviews and stakeholder input.

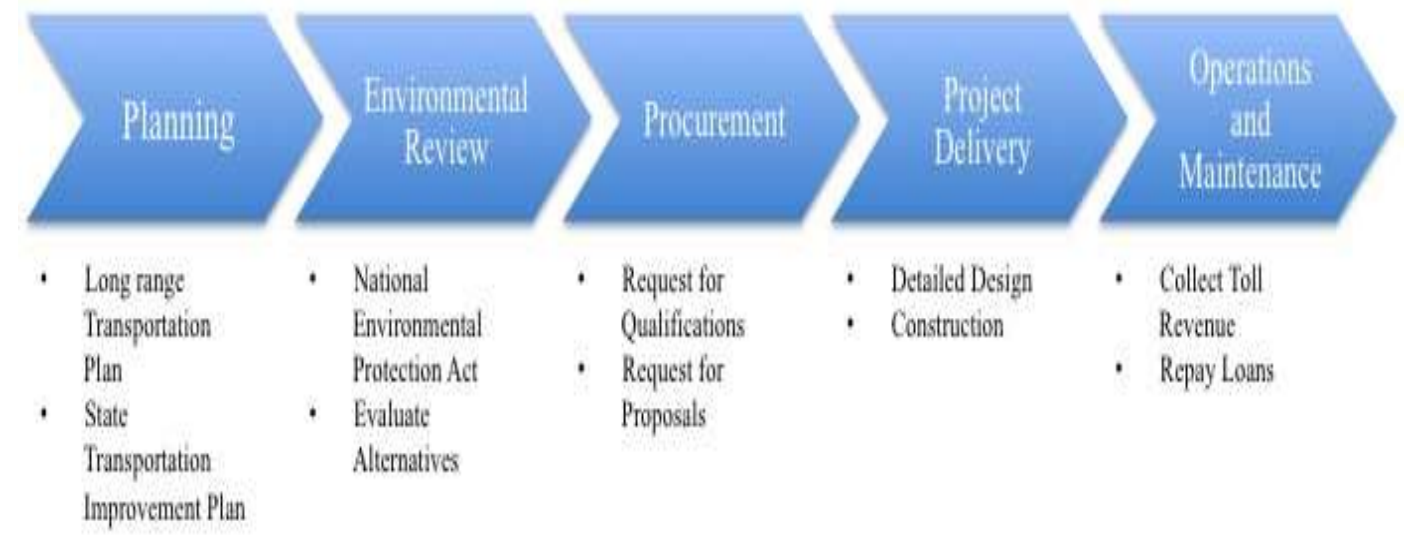

Figure 1. PPP Delivery Timeline

\subsection{Data Acquisition}

The private-entity is generating the design data necessary for the visualizations and in most cases, PDFs are the standard way of communicating the design data from the private entity to the public entity. Due to the overlap of design and construction and the expedited delivery schedule, design data is frequently changing. Also, when additional scope is added the design is not $100 \%$ complete.

As part of the public owner team, the authors address each of these challenges with a different method as shown in Table 1. 
Table 1. Data Acquisition

\begin{tabular}{|l|l|}
\hline Data acquisition challenges & Authors Actions \\
\hline PDF documents & $\begin{array}{l}\text { Develop trusting relationships with both } \\
\text { the public and private entities so the private } \\
\text { entity is comfortable providing digital } \\
\text { CAD design files to expedite visualization } \\
\text { creation with the public entity support. }\end{array}$ \\
\hline Fluid design process & $\begin{array}{l}\text { Attend design review meetings between } \\
\text { private and public entities so authors are } \\
\text { well informed of current design. }\end{array}$ \\
\hline Preliminary design & $\begin{array}{l}\text { Determine exactly what the owner's } \\
\text { concerns are and work cooperatively to } \\
\text { select which visualization elements to } \\
\text { model in detail and which elements can be } \\
\text { approximated. i.e. horizontal and vertical } \\
\text { roadway geometry need to be modeled } \\
\text { precisely, but bridge bent size can be } \\
\text { approximated. }\end{array}$ \\
\hline
\end{tabular}

\subsection{Creating Visualizations}

The visualizations used on the two case studies support decision making by showing in $3 \mathrm{D}$ what a proposed design would look like from a driver's perspective. The 3D model was created from 2D plan sheets and 2D electronic CAD files that were acquired using the methods discussed above. The authors detail the 3D modeling process in depth in Khwaja and Schmeits [4]. 3D modeling and 3D design are becoming prevalent in transportation projects. From the literature review, 3D models and 3D design have numerous documented benefits, but when creating a visual animation simulating the driver-perspective as accurately as possible, additional aspects of the project and technical details need to be considered in addition to the 3D geometry. The rendered driver-perspective animations were created by importing the 3D model into rendering software where realistic textures, lighting, signs, pavement markings, and first person cameras were used to create the most realistic driver's perspective animation for analysis. In the case study section of the paper, the authors detail all the different elements that were necessary to analyze the specific design concerns of the owner. Off-the-shelf rendering software is available from the major CAD software vendors.

\section{Case Study - LBJ Express}

\subsection{Scope of Study}

The LBJ Expressway is a corridor of I-635 between I-35E and U.S. 75 in North Dallas. It was once the second-most congested roadway segment in Texas [12]. As the project map in Figure 2 depicts, the LBJ Express Project rebuilt this corridor. In 1969 the LBJ Expressway was built to accommodate 180,000 vehicles per day (VPD). In the project area before construction, average daily traffic counts exceeded 270,000 VPD. The corridor was congested during most of the day and early evening hours. Furthermore, any incident that impacted a lane or shoulder caused additional delays. In order to relieve the congestion the LBJ Express Project

- Constructed three new express managed lanes in each direction. Drivers using these lanes are guaranteed $50 \mathrm{mph}$ travel speeds.

- Rebuilt four general highway lanes in each direction (same number as previous) 
- Provided additional shoulders

- Provided a continuous frontage road system (two or three lanes wide). Frontage roads paralleling the mainlanes are somewhat unique to Texas.

The project also included the construction of elevated managed lanes along I-35 East from Loop12 to I-635 to provide corridor-level connectivity.

The LBJ Express Project was delivered through a public-private partnership. TxDOT entered in to a 52-year concession agreement on the project ROW with a private developer, the LBJ Infrastructure Group (LBJIG), to build, finance, operate, and maintain the roadway. Initial construction cost $\$ 2.6$ billion: $\$ 490$ million in TxDOT/public funds; $\$ 664$ million in equity from LBJIG; $\$ 615$ million in private activity bonds; and $\$ 850$ million as a Federal Transportation Infrastructure Finance and Innovation Act loan. Operations and maintenance costs are estimated at $\$ 500$ million (2008 dollars). Design and construction was completed by LBJIG's design-build (DB) contractor Trinity Infrastructure (TI). Construction started in early 2011 and finished September 2015. The authors worked with the owner's project team during the delivery phase of the project.

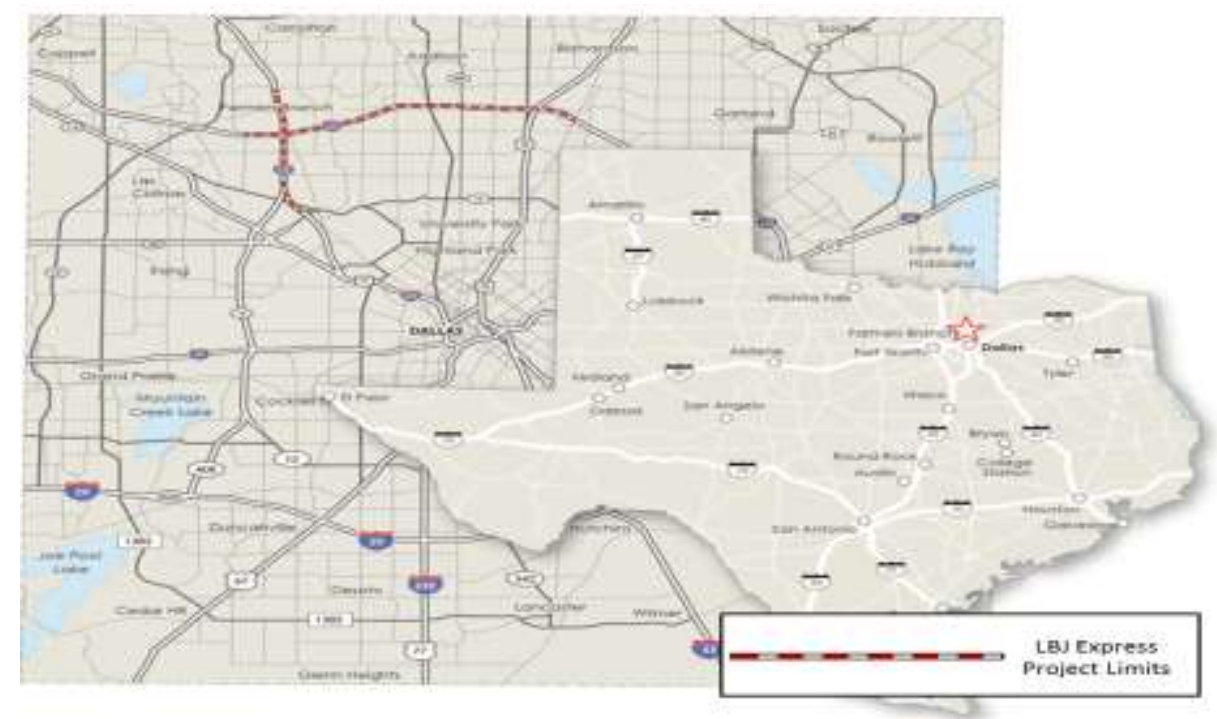

Figure 2. Project Location map of the LBJ Express Project

\subsection{Challenges}

With a project of this magnitude there are numerous challenges and innovative solutions devised, however, the paper focuses on the managed toll lanes. The LBJ Express managed toll lanes are an innovative solution to a vexing problem that planners working on this project tried to overcome, primarily due to the constraints imposed by the limited ROW and the type of infrastructure that could be build, i.e., elevated lanes were eliminated as a potential solution due to community opposition. The lanes are not a tunnel, but cannot accurately be described as a pure depressed section. Characteristics of the managed lane design are listed below and can be seen in Figure 3 and Figure 4[13]

- Managed lanes are closest to the center line of the highway

- Managed lanes are below the general highway lanes

- Partial overlap happens continuously for 3 miles and another 1 mile in a different area of the corridor

- Overlap requires part of the general highway lanes be supported by bridge 
- 3 mile long bridge requires a 7.5 foot deep bent cap to span the managed lanes every 100 feet.

- The width of the overlap between general highway lanes and managed lanes varies along the corridor

\section{1-635: US 75 to 1-35E}

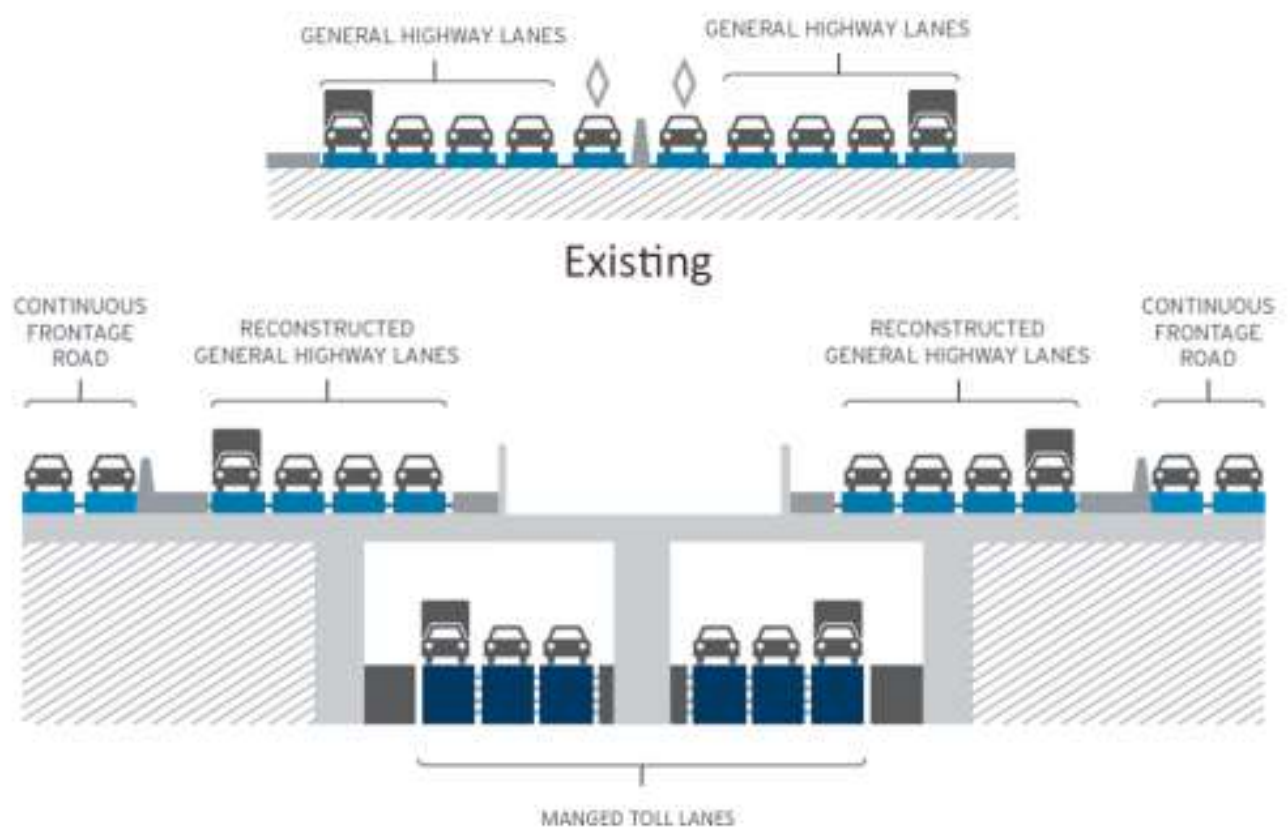

Proposed

Figure 3. Existing and Proposed Cross Sections for LBJ Express Project

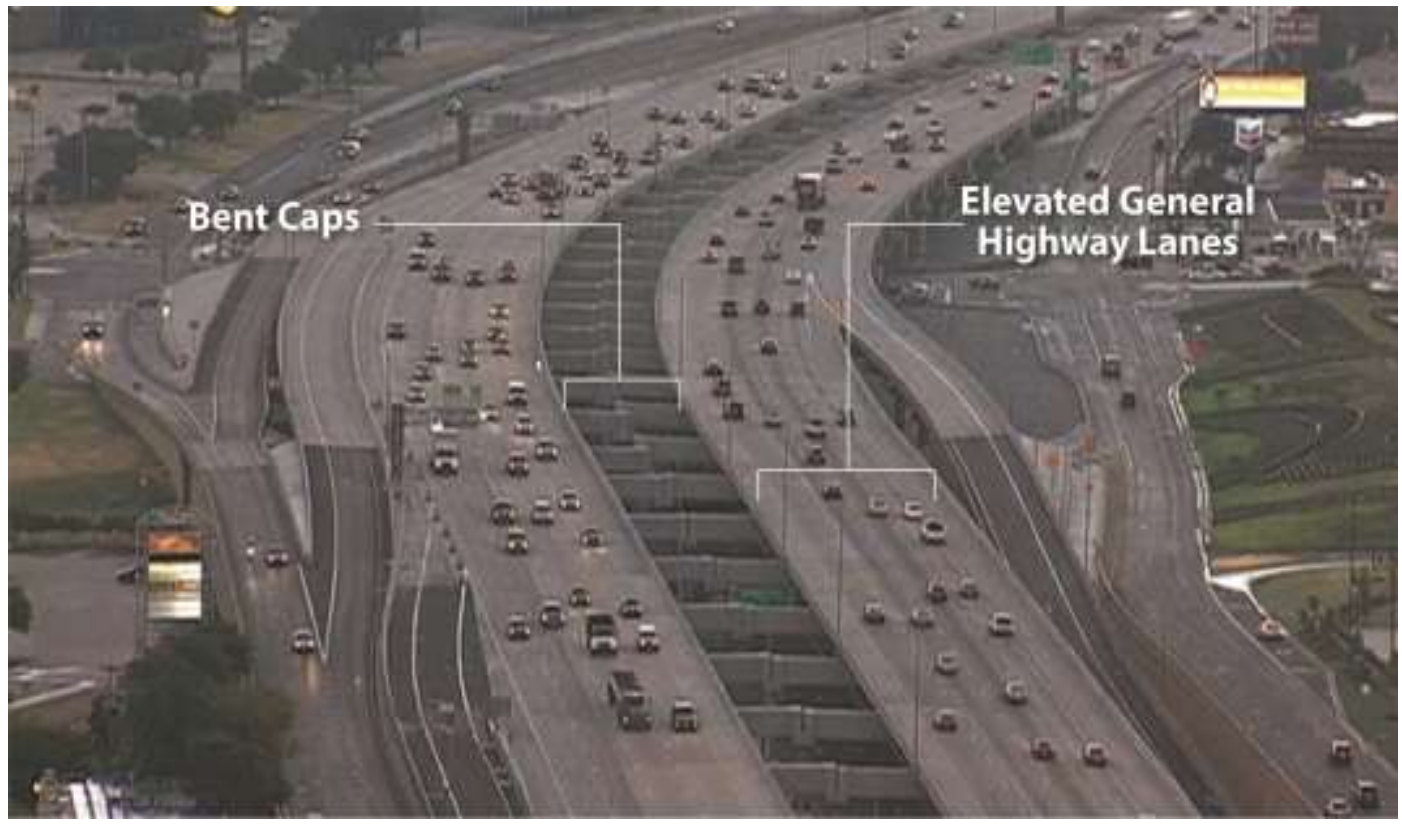

Figure 4. LBJ Express Project Showing Spacing of Bent Caps Over Managed Lanes 
During the procurement process the owner under took numerous safety analyses listed below to ensure safety to the traveling public. These safety analyses were important, but also time intensive.

- Computational dynamic modeling of smoke from a fire in the managed lanes

- Lighting models

- Traffic Modeling

- Schedule modeling

During the delivery phase the design evolved from schematic (30\%) level to construction drawings, several additional concerns were realized. One such concern was drivers' visibility of large highway guide signs. The owner wanted to ensure that the signs were clearly visible to the drivers, and the drivers had enough time to read the signs and make the necessary lane selections safely. This concern was due to the depth of the bent caps for the long bridges potentially blocking a sign or making it only visible at the last second. Due to the complex geometry of the managed lanes as mentioned in the previous section as well as the vertical and horizontal curves throughout the three mile area, traditional design documents such as elevation drawings were not deemed sufficient to evaluate and analyze this issue by the project office staff.

An additional concern raised early on in the project was about bent caps every 100 feet and how they would interact with the sunlight and affect drivers traveling at freeway speeds. There were concerns for potential strobing effect on the drivers from this interaction. This was exacerbated when the design-builder changed from a consistent overhang to a varied overhang based on ROW availability. A detailed 3D model review, which included animation of appropriate signage viewed from the drivers' perspective, revealed visible shadows that brought up the aforementioned concerns when the sun was in the driver's eyes, as well as at different parts of the day.

These challenges were intensified because of the pace at which design and construction was progressing on the project. The private sector entity was responsible for delivering this $\$ 2.6$ billion project in five years. At the height of construction operations, which was around the time this analysis was taking place, the contractor was spending approximately $\$ 2$ million per day ( $\$ 60$ million per month) to meet this aggressive delivery schedule. In addition, the owner had limited staffing (4-5 permanent engineers in the office) which made their limited time very valuable for creating a successful project.

\subsection{Implementation}

4.3.1. Signage: In order to analyze the visibility of the signage the authors utilized the previously developed 3D model and incorporated the large highway guide signs using the signage construction drawings. Station location, horizontal and vertical offset, and panel sizes were all modeled to scale directly from the construction drawings. The actual guidance information was left off the sign to expedite creating the animations, but could have been added at a later time based on the initial data collected from the drive-through. In the rendering software the camera that was used for the rendered driver-perspective animation was setup to drive at $70 \mathrm{mph}$ (proposed speed limit) at a height similar to driving a sedan in the center lane and followed all the horizontal and vertical geometry as designed. The animations showed the location of 8 signs over 6 miles for both eastbound and westbound directions to provide a comprehensive analysis for the entire managed lanes system. As seen in Figure 5, the rendered driver-perspective animations allowed for a virtual determination that there were no issues with the visibility of any of the large guide signs in the depressed managed lanes. 


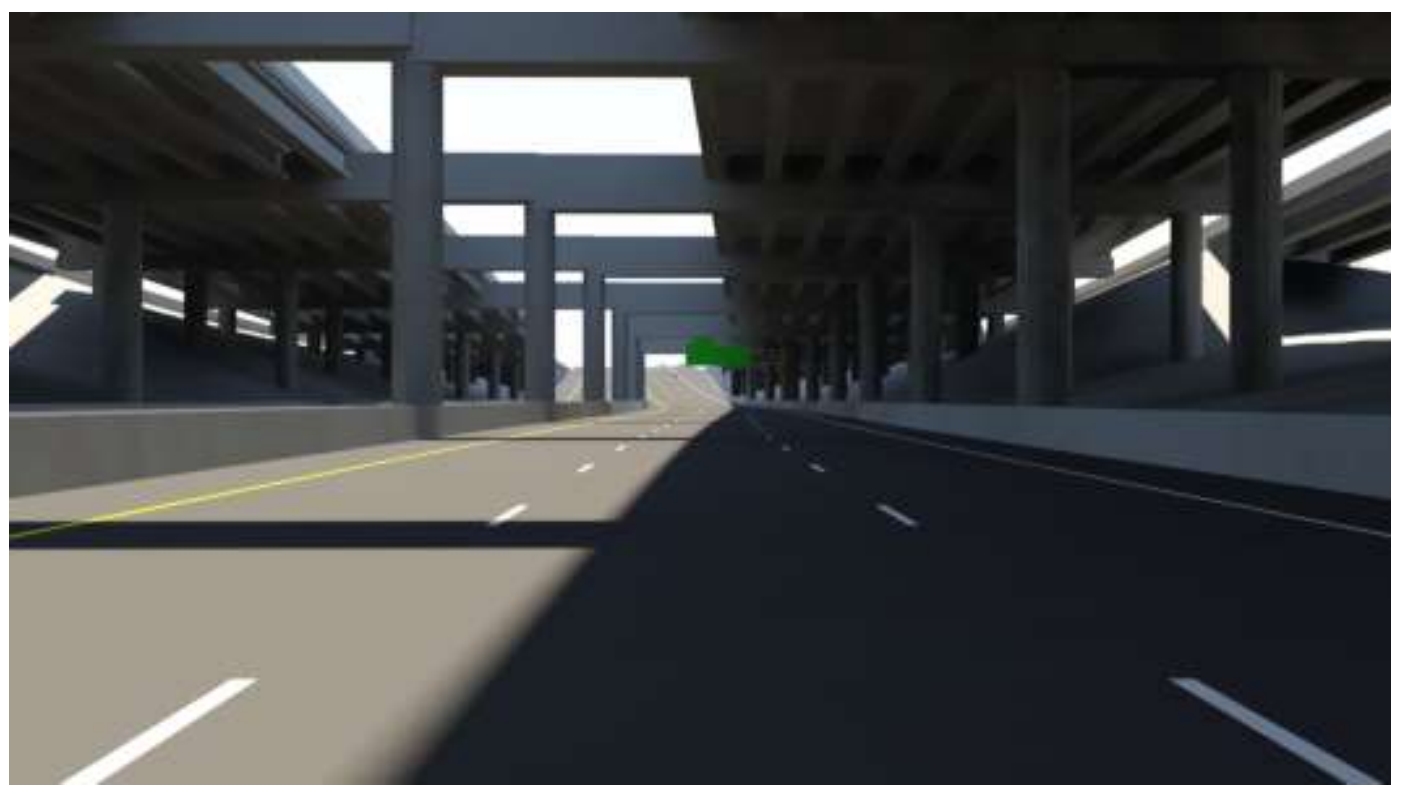

Figure 5. LBJ Express Managed Lane Signage and Sunlight Analysis Showing Clear Visibility of Overheard Signs (full video: https://youtu.be/wBTWxZRTbzg)

4.3.2. Sunlight and Shadows: The rendered driver-perspective animations and images to analyze the sunlight and shadows utilized the 3D model previously developed and the identical camera settings as in the signage animation. However, additional focus was put on lighting. Eight rendered animations were created showing both eastbound and westbound at $9 \mathrm{am}$, noon, and $3 \mathrm{pm}$ as well as when the sun would possibly be shining directly in the driver's eye. This was early morning eastbound and late evening westbound. Rendered images were taken at several locations of interest for different times of the year as well. The animation showed a driver at highway speeds travel through the entire threemile bridge area. All the horizontal and vertical geometry of the managed lanes along with bridges, retaining wall, signs, and lighting were included. As seen in Figure 5, the animations showed that there was not a flashing affect from the bent caps, but that there was a repetitious shadow pattern of the bent caps over the 3 miles of travel.

\subsection{Benefits}

4.4.1. Signage: The signage drive-through animations were able to integrate numerous highway components (horizontal and vertical geometry of the managed lanes, overhang of the general highway lanes above, depth and location of bent caps and columns, and the size and location of signing panels) from 2D sources into a 3D model for a comprehensive and thorough analysis. Traveling at highway speeds with the same views and angles an actual driver would experience added another dimension of information as well.

It is a hypothetical exercise to ascertain the precise and exact impacts of signage issues, however, it can be safely stated that discovering there was a signage visibility issue from the drive-through animations well before installing the signs or when the managed lanes were open to traffic would have provided adequate time to come up with a solution. Another certainty is that by integrating all of the elements that would affect visibility of the signage into one visual, the animations alleviated the owner concerns about signage and allowed their key staff to focus on other important issues. 
4.4.2. Sunlight and Shadows: The drive-through animations showing the sunlight and shadows were not a formal lighting analysis used to determine the number of lights necessary for design. The animation was a qualitative tool for the owner to develop an awareness of how the large bent caps and variable overhang will interact with the sun at driving speeds and at different times of the day and year. Before the drive-through animations created by the authors, the owner was not aware of an analysis completed to definitively eliminate the concern of a strobing affect. The owner, through the drive-through animation, was easily able to eliminate concern about the design's strobing affect. This particular analysis required more fusion of information than the signage analysis. In addition to all the 3D elements and animating the camera to traverse through the model at highway speeds, another dimension was added which was the sunlight. As with the signage animation, no changes needed to be made from the analysis of the animation, but the owner was able to focus their efforts on other areas of the project to ensure a successful project for the traveling public.

\subsection{Lessons Learned}

4.5.1. Cameras: Special care was taken when selecting settings for the camera that mimicked the eyes of a human. This includes field of view, blur distance, perspective distortion, etc. The settings in the videos were derived from Cicala [14].

4.5.2. Lighting: Rendering software has numerous lighting settings. A system of trial and error was needed to correctly match the existing conditions. This was done by taking a picture of a section of the managed lanes that had existing overhangs and bridges and matching that lighting. As seen in Figure 6, the animation lighting is almost identical to the actual lighting on the project.

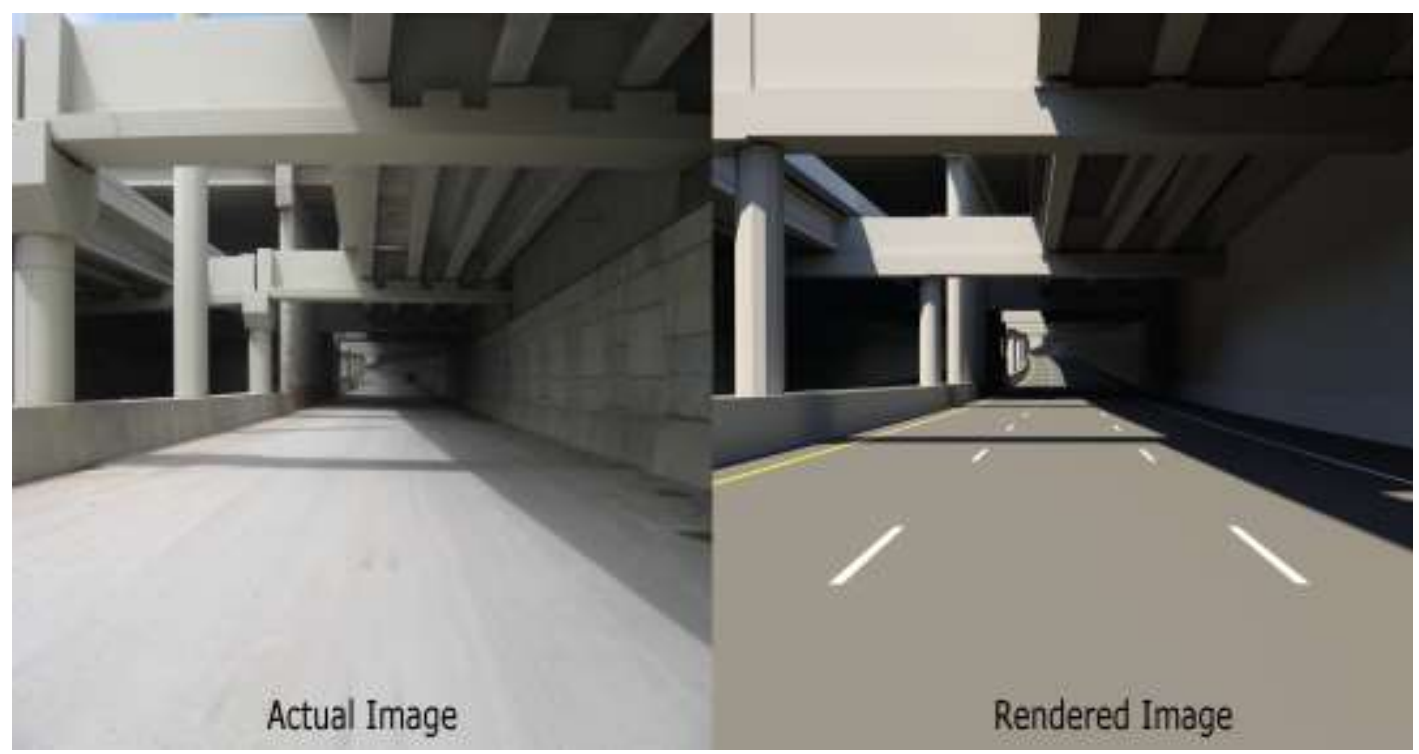

Figure 6. Comparison of Actual Project and 3D Visualization for LBJ Express

4.5.3. Speed Selection: The authors chose to create the rendered drive-through animations using the design speed to simulate a driver traveling in a vehicle. The facility has been open for almost two years and the speed limit is actually set at $75 \mathrm{mph}$. Because speed limits are the 85 percentile of what speeds drivers actually travel as recorded by a radar detector, numerous drivers are traveling at speeds above $75 \mathrm{mph}$. At the time of the analysis the facility was not open to traffic and a speed limit was not set, so the design speed was used 
in the drive-through animations. However, there could be some benefit in the future on a different project to look at higher speeds that would mimic the fastest traveling drivers within reason. The results of the analysis on this project traveling at $70 \mathrm{mph}$ did not produce any concerns that traveling much faster would have yielded different results.

\section{Case Study - North Tarrant Express 3A}

\subsection{Scope of Study}

The North Tarrant Express Segment 3A (NTE 3A) project is a corridor of I-35W between I-30 and I-820 in Fort Worth. It is the sixth most congested roadway segment in Texas [12] and fourth most congested for trucks. As the project map in Figure 7 depicts, NTE 3A rebuilds this corridor. I-35W currently carries 102,000 vehicles daily near downtown Fort Worth and 127,000 north of I-820 with eleven percent being trucks. In order to relieve congestion NTE $3 \mathrm{~A}$ will double capacity by:

- Constructing two new express managed lanes in each direction. Drivers using these lanes are guaranteed $50 \mathrm{mph}$ travel speeds.

- Rebuilding two or three general highway lanes in each direction (same number as previous)

- Rebuilding frontage roads

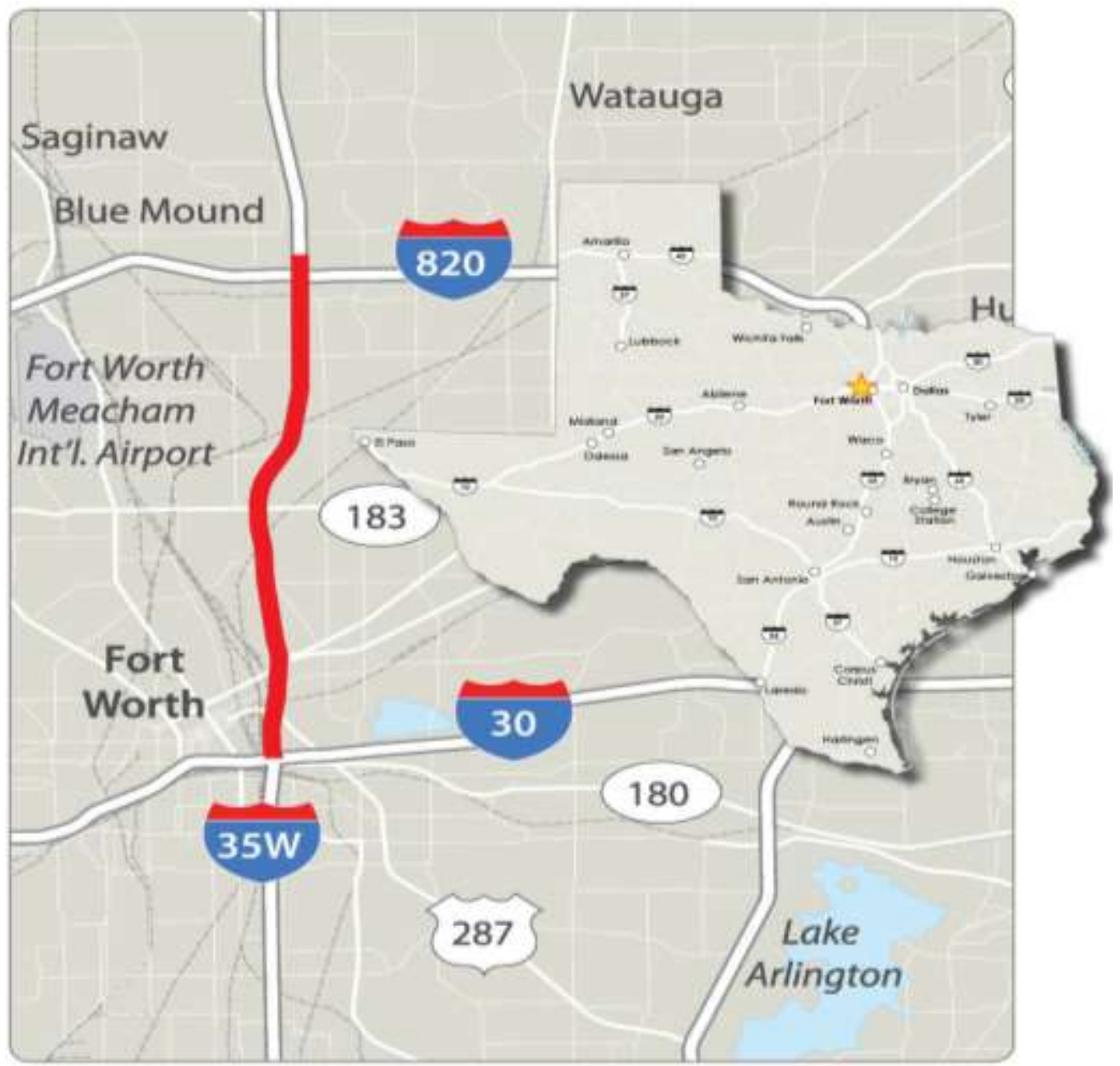

Figure 7. Project Location Map for NTE 3A 
The NTE 3A project is being delivered through a public-private partnership. TxDOT entered into a 52-year concession agreement on the project ROW with a private developer, North Tarrant Express Mobility Partners (NTEMP), to build, finance, operate, and maintain the roadway. Initial construction cost $\$ 1.4$ billion: $\$ 145$ million from the North Central Texas Council of Governments; \$442 million in equity from NTEMP; \$274 million in private activity bonds; and \$531 million as a Federal Transportation Infrastructure Finance and Innovation Act loan; \$46.5 million interest income. Design and construction is being completed by NTEMP's design-build (DB) contractor North Tarrant Infrastructure (NTI). Construction started in May 2014 and substantial completion is expected in 2018. The authors are part of the owner's team.

\subsection{Challenges}

The NTE 3A project currently under construction, called the interim version, is a reduced scope version of the ultimate project. The ultimate scope will be constructed when funding is available. During the delivery phase of the project, some additional funding was made available by the policy makers for use on the NTE 3A project. While the additional funding identified is not enough to construct all of the ultimate scope, it is adequate to build a small number of elements. The intention with the additional funding is to help improve connectivity to the new managed lanes of the NTE 3A segment.

In some areas of NTE $3 \mathrm{~A}$, the interim version under construction is designed to be compatible with the ultimate, but in other areas that is not possible due to a lack of available funding to completely reconstruct the SH121 and I-35W interchange. In this area of the project only the two managed toll lanes in each direction are being added. Compatibility with the ultimate, in this instance, means that adding a lane to a road to increase capacity or adding ramps that are a part of the ultimate scope can happen with minimal demolition of interim infrastructure (bridges, retaining walls, utilities, drainage). When the policy makers made additional funding available and the needs were identified, some of those needs were in the areas that are not compatible with the ultimate. Therefore, adding additional infrastructure without a significant amount of demolition that was not planned for, but made sense from a connect ability standpoint, requires innovative designs.

5.2.1. I-30 Connector: One of the areas requires adding a new direct connector from another major highway. As seen in Figure 8, this direct connector connects traffic from eastbound I-30 directly to the new I-35 managed lanes at the southern most end of the project. This new direct connector allows traffic from I-30 that want to take the managed lanes to bypass getting on the I-35W general-highway lanes and traveling through 2.5 miles of congested roadway in the peak travel times. Therefore, this new direct connector will very beneficial to the public.

The landing point of the new direct connector is the original (before the direct connector was added) entrance ramp of the managed lanes from the I-35W general highway lanes on the southern end of the project. This changes the configuration of the ramp the traveling public on the general-highway lanes use to enter the managed lanes. Before adding this direct connector, this entrance location was the start of the managed lanes and the inside lane of the general highway lanes was able to take the ramp into the managed lanes with out having to yield or merge to any traffic. Now with the new I-30 direct connector, the general highway lanes have to merge with traffic that, at peak times of the day, is traveling much faster than them. With limited space to fit the direct connector, a minimal acceleration and taper for the general highway lanes merging into the managed lanes was proposed that caused the owner to be concerned. This is shown in Figure 9. 


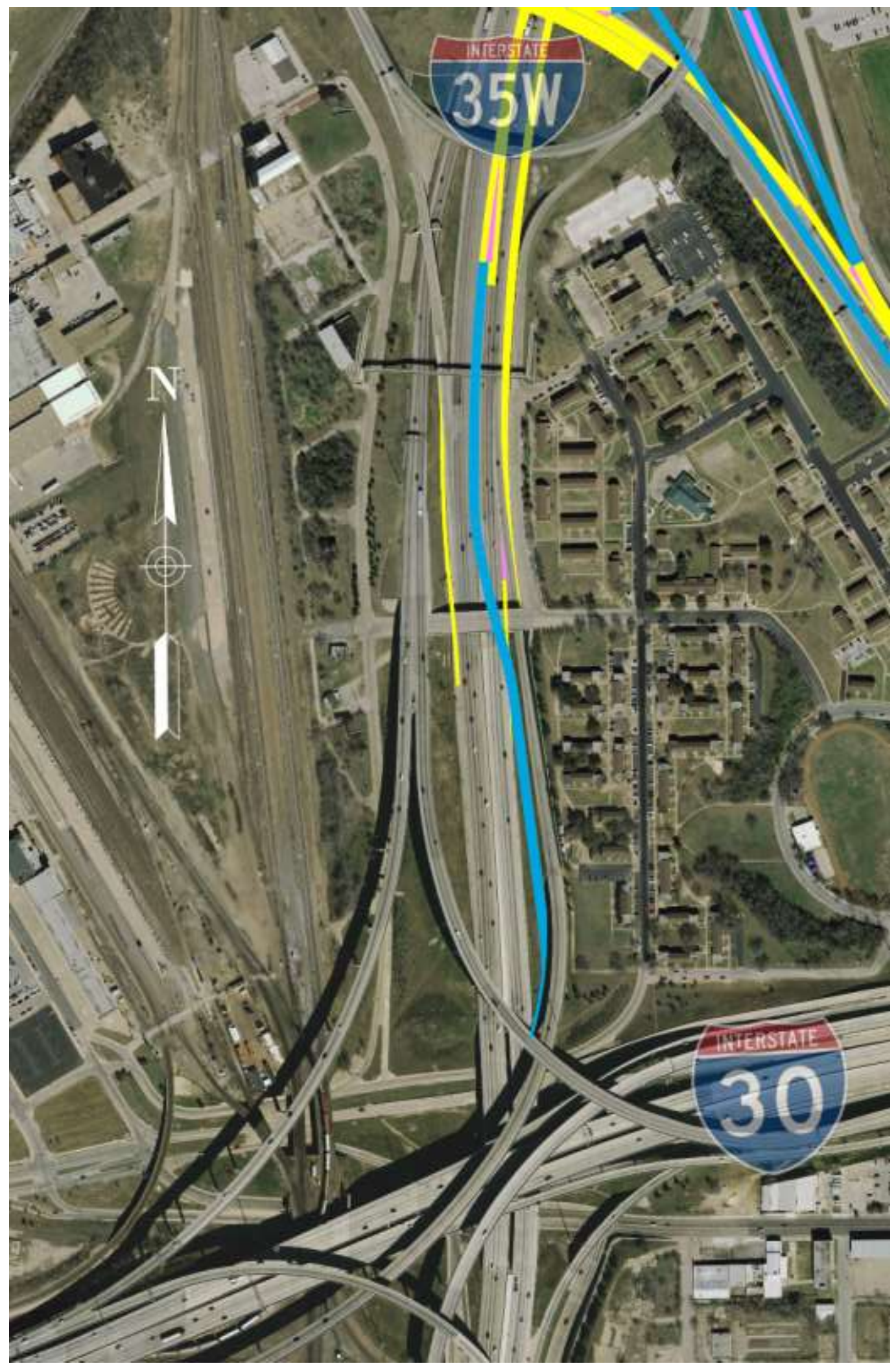

Figure 8. New I-30 Direct Connector from I-30 to I-35W Managed Lanes 


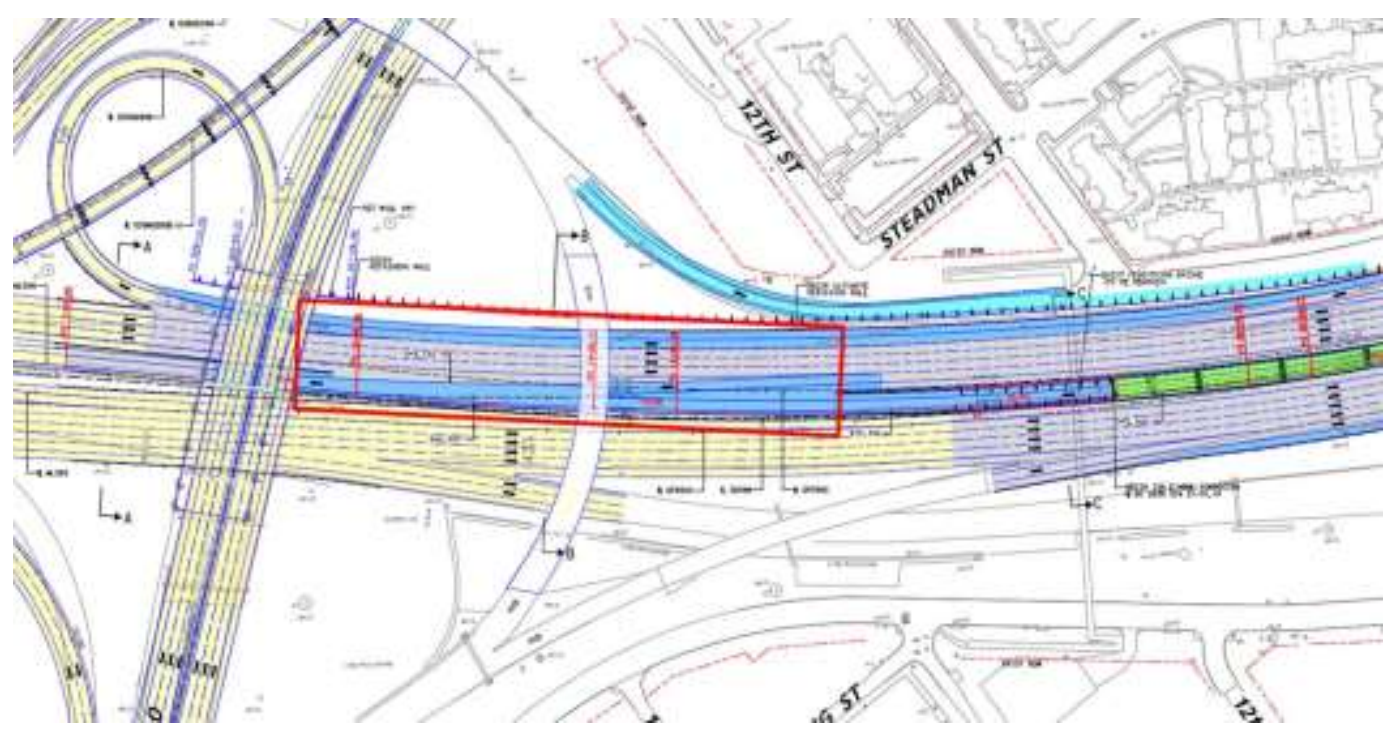

Figure 9. Plan View of I-30 Connector. Merge Area Shown Inside Red Box

5.2.2. Downtown Connector: Two new direct connectors that connect State Highway 121 near downtown Fort Worth and the managed lanes to the north were also proposed with the additional funds. As seen in Figure 10, both are bridges where one will bring traffic into downtown from the north and the other will take traffic from downtown. The area of SH121 where the new direct connectors will attach near downtown are bridges that have an ornamental rail that is valued by the city for its aesthetic appeal as seen in Figure 11. The developer originally agreed to have the parts that split from the main bridge of the direct connector to have the ornamental rail, but later proposed to do only a small section where the new ramps joins SH121. The developer's thought was the rail would not be seen by the traffic on SH121 coming into and leaving downtown.

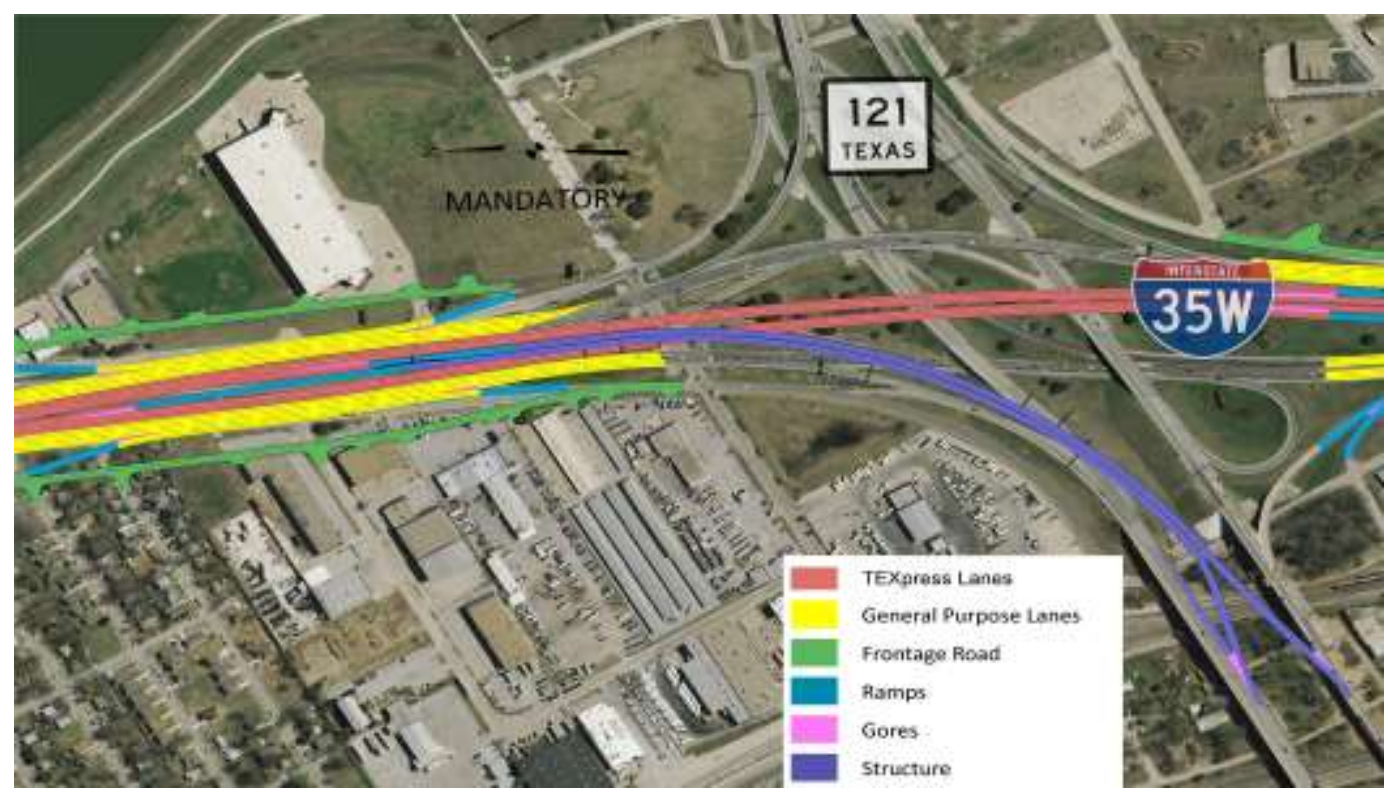

Figure 10. Downtown Direct Connectors to/from I-35W Managed Lanes to the North (shown in purple) 


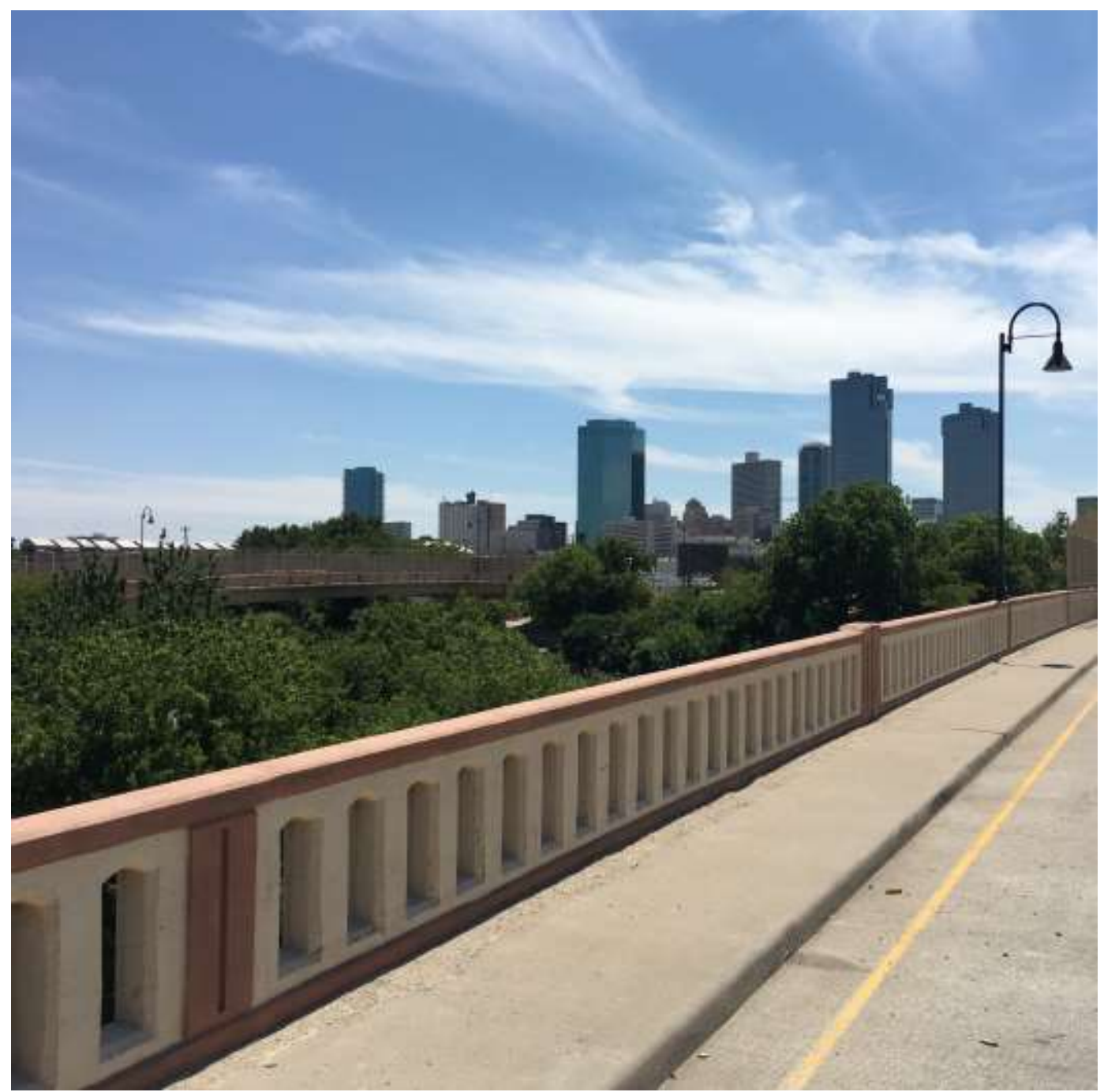

Figure 11. Ornamental Rail on SH 121 Near Downtown Fort Worth (in background)

Just as with the LBJ Express project, all of these challenges were intensified because of the pace at which construction was progressing. At the height of construction operations, which was around the time this analysis was taking place, the contractor was spending approximately $\$ 40$ million per month to meet the delivery schedule. In addition, the owner had limited staffing (3-4 permanent engineers in the office) which made their limited time very valuable for creating a successful project.

\subsection{Implementation}

5.3.1. I-30 Connector: In order to simulate what a driver on the general highway lanes that wants to merge into the managed lanes would see, a rendered driver-perspective animation was created. The animation included all the necessary 3D elements modeled to scale. Those elements are the horizontal and vertical geometry of all roadways involved, all bridge elements, retaining walls, and pavement markings. The barrier and retaining wall were important because the merging general highway lanes need to be able to find a gap in the direct connector traffic and the retaining wall and barrier could hinder the drivers view. As seen in Figure 12, the animation simulated a driver traveling in the left lane at the maximum design speed $(60 \mathrm{mph})$ at a height similar to driving a sedan. After traveling in the left lane, 
the driver goes through the merge area and in order to simulate finding a gap the camera rotates just as a drivers head would and then rotates back forward to identify what bailout scenarios are available if they cannot find a gap.

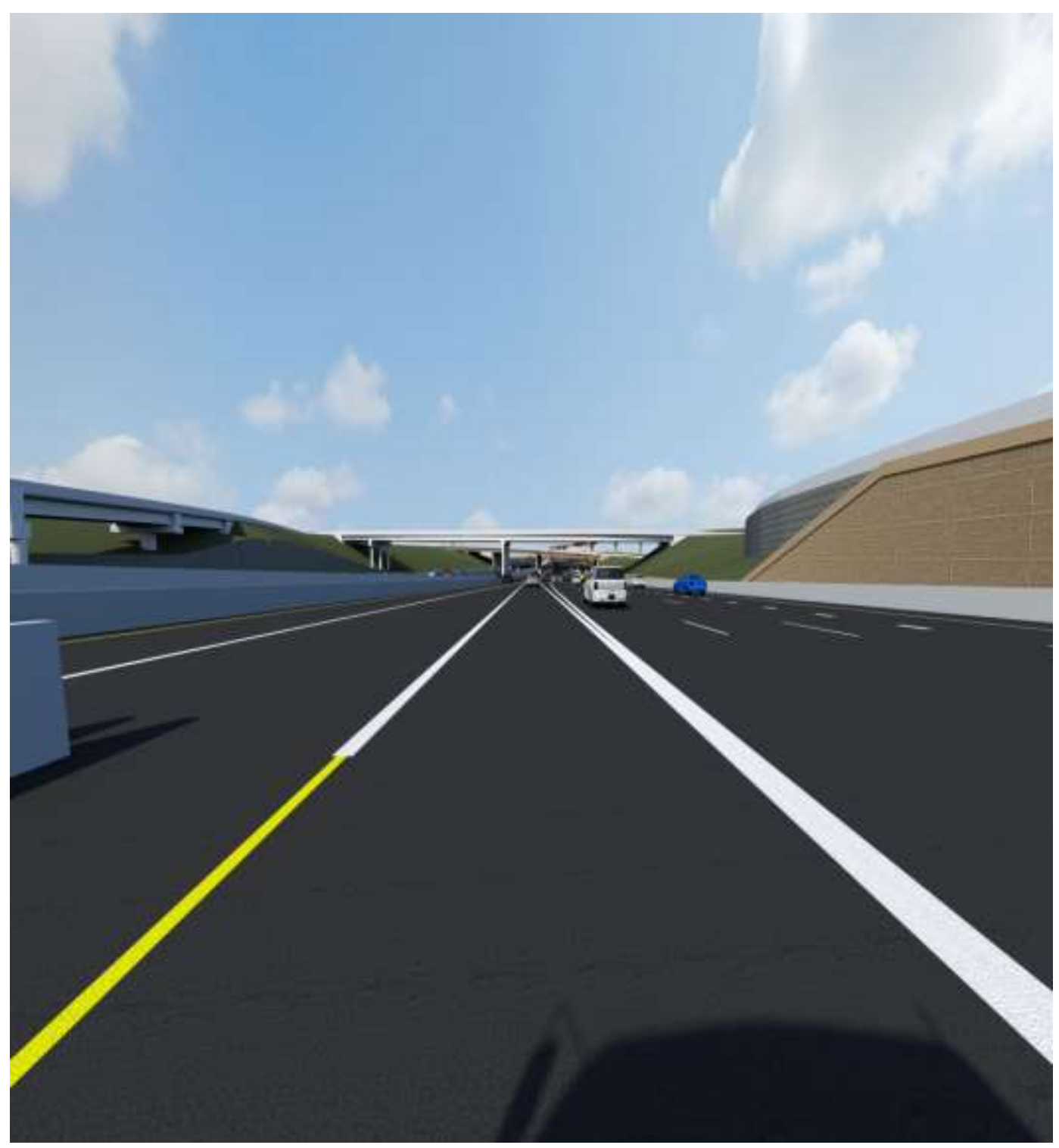

Figure 12. Driver's Perspective of General-Highway Lane Merge Area for I30 Connector (full video: https://youtu.be/zBZiypr7-ho)

5.3.2. Downtown Connector: In order to simulate what a driver on the main lanes of SH121 (highway currently with ornamental rail that leads into and out of downtown Fort Worth) a rendered driver-perspective animation was created. The animation included all the necessary elements modeled to scale. For this animation retaining walls and bridges were not necessary, however correct rail heights and a fence along SH121 needed to be added to the horizontal and vertical geometry of the roadways involved. In order to highlight the rail that was in question, it was colored green. As seen in Figure 13, the animation simulated a driver traveling in the left lane at the maximum design speed at a height similar to driving a sedan. The animation includes both directions into and out of downtown to ensure a thorough analysis. The animation clearly showed that drivers on $\mathrm{SH}$ 121 driving into and out of downtown could see the rail in question. 


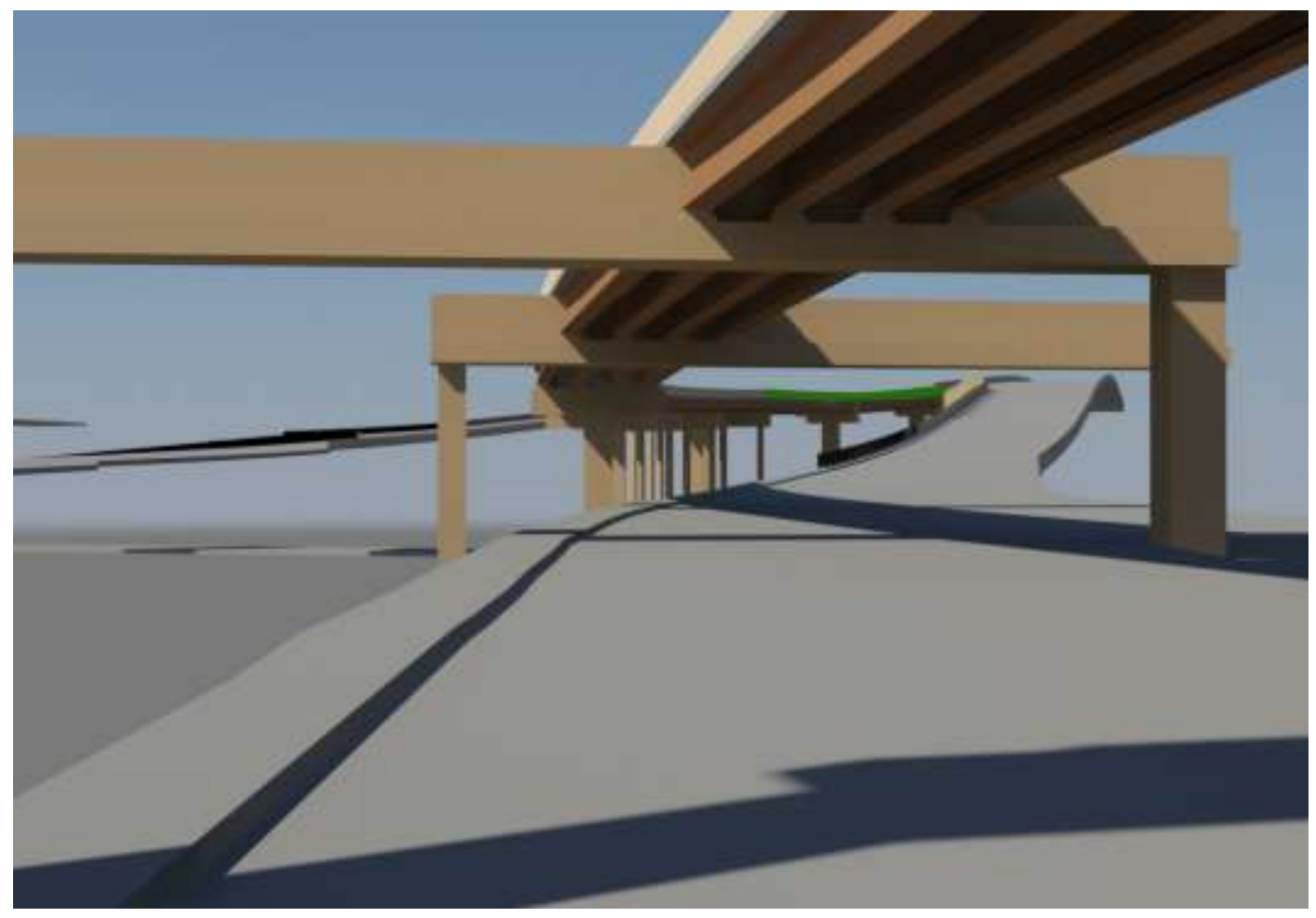

Figure 13. NTE 3A Downtown Direct Connector Rail Analysis. Rail is Shown in Green. (full video: https://youtu.be/x819TIIWU4E)

\subsection{Benefits}

5.4.1. I-30 Connector: After viewing the rendered driver-perspective animation, the owner's team was able to see that the location of the merge point could be moved further from the entrance of the general highway lanes, thus creating more room for acceleration and merging by the general highway traffic. A column in the distance was the controlling factor that limited how far the merge point could be moved. This merge location is in the interchange of I-35W and US287 where several direct connectors are present. Also, this area is all bridge because the highway is crossing over a railroad. The 2D design schematic had been looked at and analyzed dozen of times, but as discussed above there is a lot of information to display in a simple 2D schematic. Seeing all of the design elements in 3D from a driver's perspective provided a new, information-rich, perspective with which to analyze the design. The merge area is being redesigned and will be reviewed again both in $2 \mathrm{D}$ and $3 \mathrm{D}$ to gather as much information as possible.

5.4.2. Downtown Connector: The rendered driver-perspective animation was able to integrate all of the different elements that could have had an effect on the visibility of the ramp into a $3 \mathrm{D}$ animation. It was a very concise and easily understood presentation that showed what would be visible once the new direct connector was built. This allowed all parties to discuss the importance of the ornamental rail and make an informed decision with minimal doubt. The animation was able to save valuable meeting time and debating time between the parties. This is of high importance when the project is under construction and delays are very costly.

\subsection{Lessons Learned}

The timeframe to edit the 3D model and produce the downtown connector animation was approximately two weeks. This required the authors to be selective and prudent with 
what elements of the model were most relevant to the issue at hand. The bridges underneath the roadways would not make an impact on the visibility of the rail so they were left as is. The height of the existing rail and an existing fence along SH121 could have had an impact on the visibility of the rail so they were added to the model.

\section{Conclusion and Recommendations}

PPPs are conducive to delivering large and complex projects with innovative design solutions and a rapid schedule. This paper details two case studies where 3D visualizations were successfully used to support decision analysis by the owner's team during the delivery phase of the PPPs. The 3D visualizations on these case studies have presented a roadmap for owners that need the fusion of complex engineering information in a realistic 3D environment to assist them with making a decision in a timely manner. The rendered drivethrough animations were able to eliminate several concerns so the owner's team could focus on other challenges of the project. The limited number of owner staff tasked with delivering the large projects strained their time and resources. Therefore, concise and easily understood visualizations that integrated all the relevant information was very valuable. The rendered drive-through animations also provided clear information for meaningful discussion between the public and private entity owner. As documented in the literature review, visualization has numerous benefits, but lacked the details about how they could be employed during the delivery phase of a PPP. With increased population and demand for more capacity, fast paced projects and innovative designs will become more commonplace and these tools will continue to be of value.

Through the use of the latest in visualization and modeling technology the owner's project team was able to analyze complex engineering and design quality issues to their satisfaction quickly and efficiently. For the future, the addition of accurate traffic information would allow for modeling more accurate operational conditions. This would have been particularly helpful for the I-30 connector merge area on NTE 3A.

Also, this paper has noted several areas where 3D visualization provided clarity and significant time savings. These are clearly defined benefits, but ones that are hard to assign a numerical value for. As 3D design and 3D visualization become more commonplace, research should continue on trying to quantify some of the benefits.

\section{Acknowledgement}

The authors would like to thank the Texas Department of Transportation's Dallas and Fort Worth's offices for helping provide significant assistance and data for completing this work.

\section{References}

[1] Texas Department of Transportation "Current Comprehensive Development Agreement", <http://www.txdot.gov/government/partnerships/current-cda.html> Accessed July 13, 2017.

[2] K. Nees and P. Bailey-Campbell, "Private on the I's", Roads \& Bridge Magazine, (2006) March, pp. 4446.

[3] W. J. O’Brien, P. Gau, C. Schmeits, J. Goyat and N. Khwaja, "Benefits of Three- and Four-Dimensional Computer-Aided Design Model Applications for Review of Constructability", Transportation Research Record: Journal of the Transportation Research Board, No. 2268, (2012), pp. 18-25.

[4] N. Khwaja and C. Schmeits, "Improving the Transparency of Construction Project Through Visualization Technology", Transportation Research Record: Journal of the Transportation Research Board, No. 2408, (2014), pp. 34-43.

[5] K. A. Liaip, "4-D Visualization of Highway Construction Projects", Proceedings of the $7^{\text {th }}$ International Conference on Information Visualization, London, England, (2003), pp. 639-644.

[6] C. Kim, H. Kim, T. Park and M. K. Kim, "Applicability of 4-D CAD in Civil Engineering Construction: Case Study of a Cable-Stayed Bridge Project", Journal of Computing in Civil Engineering, vol. 25, no. 1, (2011), pp. 98-107. 
[7] J. Upchurch, D. Fisher, R. A. Carpenter and A. Dutta, "Freeway Guide Sign Design with Driving Simulator for Central Artery-Tunnel", Transportation Research Record: Journal of the Transportation Research Board, No. 1801, (2002), pp. 9-17.

[8] G. Consolazio, "4-D Drive-through Visualization of I-280 for Review of Proposed Signing”, FHWA-NJ1999-002. FHWA, U.S. Department of Transportation. (1998).

[9] K. Han, D. Middleton, W. J. Muzycza, S. Minty and A. Clayton, "Developing Virtual Reality Visualizations to Support Highway Geometric Design", Proceedings of the $3^{\text {rd }}$ International Symposium on Highway Geometric Design, Chicago, Illinois, (2005) June 29-July 1.

[10] Y. Hasan, S. M. Easa and A. O. Abd El Halim, "Highway alignment: Three-Dimensional Problem and Three-Dimensional Solution”, Transportation Research Record: Journal of the Transportation Research Board, No. 1612, (1998), pp. 17-25.

[11] K. R. Santiago-Chaparro, M. DeAmico, A. Bill, M. Chitturi and D. A. Noyce, "Virtual Road Safety Audits Using Driving Simulators: A Framework", Proceedings of the $3^{\text {rd }}$ International Conference on Road Safety and Simulation, Indianapolis, United States, (2011) September 14-16.

[12] Texas Department of Transportation, "100 Most Congested Roadway Segments in Texas." Texas Transportation Institute < http://apps.dot.state.tx.us/apps/rider56/list.htm> Accessed August 1, 2012, (2010).

[13] Fox 4 News, "LBJ Express officially opens in Dallas" <http://www.fox4news.com/news/18440402story> Accessed April 12, 2017.

[14] R. Cicala, "The Camera vs. The Eye", Lensrental <https://wordpress.lensrentals.com/blog/2009/03/thecamera-vs-the-eye/>(2009) Assessed July 14, 2015.

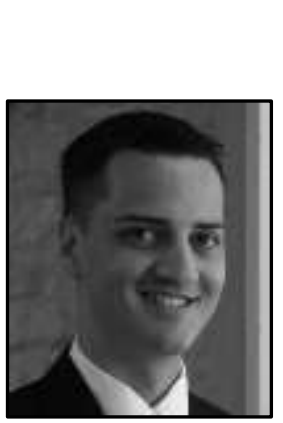

\section{Authors}

Cameron Schmeits, Mr. Schmeits is a Research Associate in the Dallas-Fort Worth region for the Center for Transportation Research of the University of Texas at Austin. He started working in the visualization field in 2009 as a graduate research assistant at UT Austin working with Nabeel. After getting his master's degree in 2011 he started as a Research Fellow working full time on the LBJ Express project doing visualization. Since then he has also worked on the North Tarrant Expressway project. Mr. Schmeits currently lives in Flower Mound, TX.

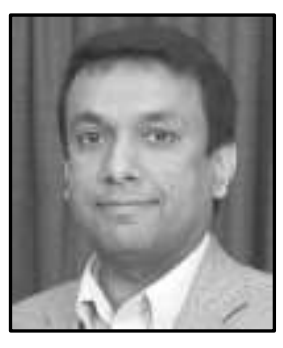

Nabeel Khwaja, P.E., Mr. Khwaja leads the Dallas and Fort Worth group of CTR. Since 1998 he has managed a diverse portfolio of research and implementation projects for the Center. His primary focus has been the implementation of research on the constructionphase delivery of infrastructure projects, advanced construction tools and technologies, project and portfolio control systems, project decision support systems, information technologies and project data analytics. During his career working in the Dallas-Fort Worth metropolis he has calibrated and implemented research to mitigate the impacts of construction on the traveling public. Mr. Khwaja lives in Garland, Texa 